\title{
La voz del lugar, el lugar de la voz: cartografías ciudadanas
}

Victoria Martínez-Vérez. Universidad Nacional de Educación a Distancia, A Coruña, España.

Antonio Montero-Seoane. Universidad de La Coruña, A Coruña, España.

RESUMEN | En este trabajo de arte de acción hilamos diferentes voces al tejido urbano, construyendo un diálogo interpersonal en el que personas distintas, habitantes todas ellas de un espacio social determinado, relatan la vivencia que el lugar teje en su topografía interior. La piedra, arquitectura simbólica de ese yo que se establece en unas coordenadas y que espera ser hallazgo de un otro, se transforma a través del arte de acción en un canal de comunicación para los habitantes del lugar. El relato de las vivencias topográficas ofrecido por la ciudadanía es analizado mediante una variante de la metodología de estudios de panel (Sun Woong, 2008), denominada "de cohorte" (De Keulenaer, 2008), para trazar una cartografía hablada de la ciudad, identificando las diferencias de los discursos humanos surgidos en los usos sociales de cada espacio.

PALABRAS CLAVE | geografía social, imaginarios urbanos, participación ciudadana.

ABSTRACT $\mid$ In this art action project we join different voices to the urban fabric, building an interpersonal dialogue in which different people, all of which live in a given social space, relate the experience of that space in their inner topography. The stone, symbolic architecture of that self that stablishes coordinates and hopes to be found by other, is transformed by art in action in a communication path for the location's inhabitants. The account of the topographic experiences offered by the citizenship is analysed using a variant of the panel studies participatory methodology (Sun Woong, 2008), called "cohort" (De Keulenaer, 2008), which allows to identify the differences of the human experiences born from the social uses of each space, with the use of spoken maps of the city.

KEYWORDS | social geography, urban imaginaries, citizen participation.

Recibido el 11 de mayo de 2018, aprobado el 28 de enero de 2019.

E-mails: V. Martínez-Vérez, vita.martinez.verez@gmail.com | A. Montero, antonio.montero.seoane@udc.es 


\section{Introducción y estado de la cuestión}

\section{El abordaje de la comunicación emocional a través del arte de acción como herramienta cartográfica}

Las emociones, tan humanas como la piel, parecen existir al margen de toda topografía, sin raíz, lejos de cualquier coordenada de situación. Tienen nombre, concepto asociado y conducta relacionada. Incluso, según señalan las diferentes leyes educativas espańolas, su estudio es obligatorio, pero sucede que, al no estar localizadas en el cuerpo sensible del territorio personal y social, es como si se negaran.

En la práctica, la gestión emocional es abordada en todas las etapas escolares, así como en la formación laboral específica, mediante un conjunto de aprendizajes cognitivos propios de un sistema tecnócrata de enseńanza (Ortega, 2013). Son aprendizajes que permiten a las personas desbrozar semánticamente los conceptos (Giráldez \& Prince, 2017), pero sin vivenciarlos en lo cotidiano y, por lo tanto, sin ubicarlos en las instancias personales (Yo-Otro), y tampoco en el espacio-tiempo. Existen, sí, pero sin referencia.

Todo aquello que carece de lugar concreto resulta inabordable (López Cao, 2014), y es por eso que, desde la antigüedad más remota, el ser humano ha necesitado de los mapas, los cuales no solo señalan e indican dónde y cuándo, sino que permiten comparar y realizar asociaciones de conceptos como clima y región u orografía y tiempo, por ejemplo.

En este contexto, por un lado cartográfico, en relación con la citada necesidad de situar aquello que se siente en el marco de un territorio; y por otro legislativo, respecto a la obligación de enseńar conceptos relacionados con la inteligencia y la comunicación emocional, surge la idea de llevar a cabo un proyecto innovador que teja el pensamiento íntimo del individuo en el ámbito de la geografía social.

Para llevarlo a cabo se eligió una metodología que permitiera la actuación grupal, en el marco del territorio ciudadano, con el objetivo de escuchar las emociones que surgen en un espacio determinado. Para ello, tras analizar varias opciones, se optó por el arte de acción, ya que, como señalan, entre otros, Bartolomé (2017), Mora (2013), y Zaragoza, Luis-Pascual y Manrique (2009), desde un punto de vista didáctico, los procesos creativos permiten trabajar aspectos relacionados con la inteligencia emocional, incluyéndola en el eje metodológico como herramienta mediadora.

El arte de acción se caracteriza por los siguientes rasgos:

- Es un excelente mediador educativo, ya que promueve la vivencia emocional compartida (Moreno, 2015; Tejo, 2017).

- Se desarrolla en el campo social, en el tiempo presente, e incluye a la ciudadanía como parte protagonista del proceso artístico.

- Tiene un marcado carácter procesual que pone el acento no en el resultado final de la obra, sino en la significación de las acciones, tanto individuales como colectivas, permitiendo la convivencia de diferentes subjetividades en un mismo proyecto. 
- No participa del mercado del arte, ya que se desarrolla únicamente en la comunidad de referencia y resulta difícil de exponer, comprar y/o vender.

- Permite expresar, a través de la práctica, los sentimientos que trascienden al individuo, en lugar de memorizar los conceptos asociados a los mismos (Terrones, 2013).

- Se trata de una práctica efímera, que no tiene como finalidad perdurar en el tiempo, sino dar trascendencia al tiempo dedicado a la práctica artística.

- Es performativo, en cuanto posibilita la vinculación de las personas con la percepción que nace de la vivencia compartida de un mismo proceso artístico, favoreciendo el intercambio de significaciones (Segura \& Simó, 2017).

- Debido a este carácter dinámico y continuo, el arte de acción genera micronarraciones en lugar de una sola narración, al permitir que los relatos de los participantes (emisores o receptores) convivan con otros más amplios (Zaliasnik, 2017).

- Su necesaria práctica colectiva y participativa constituye en sí misma una metodología de aprendizaje horizontal que genera un conocimiento experiencial, en lugar de uno vertical y transmisivo, de modo tal que el cartógrafo emocional aprende a través de la exploración personal y grupal del terreno que pisa.

\section{Cartografía de la voz humana}

La voz humana, además de habitar el pensamiento, se agita en la concreción de unas coordenadas físicas que evocan recuerdos, correlacionan ideas, enlazan espacios con usos sociales y privilegian unas conversaciones sobre otras.

Existe, pues, una línea tangencial entre el lugar y las personas que lo habitan, dibujando una geometría precisa conformada por la arquitectura del espacio, la necesidad social que determina la planificación urbanística, y el imaginario de la persona que diseña ad hoc. En los ángulos que trazan esta figura, danzan, al libre albedrío, las voces de las personas que dan forma al lugar, redibujando los límites de la estructura con su propia impronta. En ocasiones, el diálogo entre lugar, función, diseńo y voz es el proyectado, pero otras no, y es, precisamente, en esas disonancias del trazado donde habita el verbo humano creando nuevos usos, costumbres y lenguajes; así, se puede decir que la voz es el lápiz de grafito que completa la acción del arquitecto (De Bustos, 2000); sin la comunicación social, el diseño estaría inacabado.

Todos, en alguna ocasión, nos hemos preguntado por las palabras que dirían las paredes de los espacios que habitamos. El ser humano necesita proyectar su memoria, pero ¿es posible escucharla?; y no solo eso, sino también, ¿tiene la voz algún poder creador, respecto al uso social del lugar? Y si lo tiene, ¿`cómo se podría determinar el peso de la misma en el diseño arquitectónico?

Existen mapas de todas clases, conceptuales, de carreteras, de territorio físico y político, cosmológicos, corporales, etcétera; incluso existen atlas sociales, psicogeográficos (Guy Debord, París, 1958), artivistas (Thomas Hischhorn, Berlín, 1957; y Öyving Fahlström, São Paulo, 1928; Estocolmo, 1976) y participativos (Creative 
Mapping, Institute of International Visual Arts, Londres, 2007). Cualquier cartografía enlaza el conocimiento comprensivo de una persona con el anhelo de saber de otra, en una metáfora de la realidad percibida, y lo hace trazando en un mismo plano conexiones visibles e invisibles que permiten a los destinatarios enlazar conceptos, puntos, posiciones, reivindicaciones, tiempos, etcétera.

En este sentido, se puede decir que, desde siempre, el ser humano ha necesitado conocer el mundo, imaginarlo y posicionarse en él, atendiendo a aquello que le interesa (Macaya, 2017). A fin de cuentas, saber llegar a unas coordenadas, recorrer una senda imaginaria, comprender la totalidad de una idea, soñar un lugar lejano, son deseos humanos.

De todos los tipos de mapas existentes, los participativos quizás sean los más adecuados, tanto para escuchar la voz del lugar, como para establecer las relaciones que existen entre el espacio, la función social que determina su arquitectura, y la voz creadora de las personas que los habitan de palabras, ya que su objeto es analizar los vínculos entre las personas y los entramados urbanos, mapeando inquietudes, problemáticas y emociones, a través de juegos de significado que permitan conectar conceptos tan poco convencionales como complejos. Así, este tipo de investigación narrativa permite abordar sistemáticamente la experiencia y los significados personales de los acontecimientos vividos por sujetos activos en un tiempo y lugar, creando nuevos escenarios para el argumento narrativo (Kramp, 2004).

A nivel metodológico, para trazar una cartografía de la voz humana es necesario contar con la participación de la comunidad de referencia; acotar el terreno en el que habita; establecer un método creativo que permita observar sistemáticamente la declinación verbal; proponer un lenguaje común que vincule la libertad de la palabra al folio de la investigación; y buscar un modo de generar conocimiento útil para las personas que deseen explorar el territorio social representado (Kara, 2015). Para que una cartografía sea provechosa, debe mostrar aquello que se quiere encontrar, de forma que nadie se pierda en su interior.

Este trabajo de investigación, situado en el cruce interdisciplinar de la comunicación humana y del ejercicio de ciudadanía, trata de representar el sonido de las voces que construyen los lugares que habitamos, completando, con su eco, la acción de la arquitectura, en un trazado vivo y poético de todo aquello que nos conmueve a ser en relación.

\section{Material y métodos}

\section{Metodología}

Para alcanzar este objetivo, en el curso 2016-2017 se propuso al alumnado del módulo de habilidades sociales, de los Ciclos Superiores de Educación Infantil e Integración Social, del Centro Integrado de Formación Profesional Anxel Casal, definido como referencia para la región gallega, la posibilidad de crear un diálogo colectivo que recogiese las diferentes voces anónimas que recorren la ciudad de A Coruña (España), a partir de la siguiente hipótesis: ¿es la arquitectura de la voz la que da sentido al lugar que la habita, diferenciándolo de otros lugares distintos? 
O, más bien, ¿es el uso social del espacio una variable indiferente en la arquitectura del discurso humano?

La práctica artística de la profesora encargada de la asignatura y coautora de este artículo, Victoria Martínez-Vérez, así como su participación como investigadora en dos proyectos de innovación educativa, promovidos por la Universidad de Vigo en el marco de las convocatorias ministeriales de los cursos 2014 y 2017, dotó de rigor y de trascendencia al proyecto.

Proceso artístico: la voz del lugar, el lugar de la voz

El proyecto cartográfico "La voz del lugar, el lugar de la voz", destinado a hilar el discurso ciudadano con el lugar del habitante, se desarrolló en varias fases.

En primer lugar, tuvo lugar la elección de un objeto simbólico, la piedra, que actuó como canal de comunicación (figura 1). Dicha elección se realizó atendiendo a cuatro razones: se trata de un objeto cartográfico, costero, propio del territorio, de fácil obtención, que permite la escritura y la grafía simbólica; y que, al generar "extrañamiento", despierta la curiosidad del interlocutor (Terrones, 2013). Además, desde un punto de vista simbólico, en Galicia, desde la antigüedad, los milladoiros de piedras, situados en puntos determinados del camino al finis terrae marítimo, simbolizaban la presencia de aquellos que alcanzaron su propio destino, interior o exterior. Así pues, la piedra escrita representa el yo, que habla a un otro, al que interpela, estableciendo de este modo una relación entre voz, presencia, topografía y palabra.

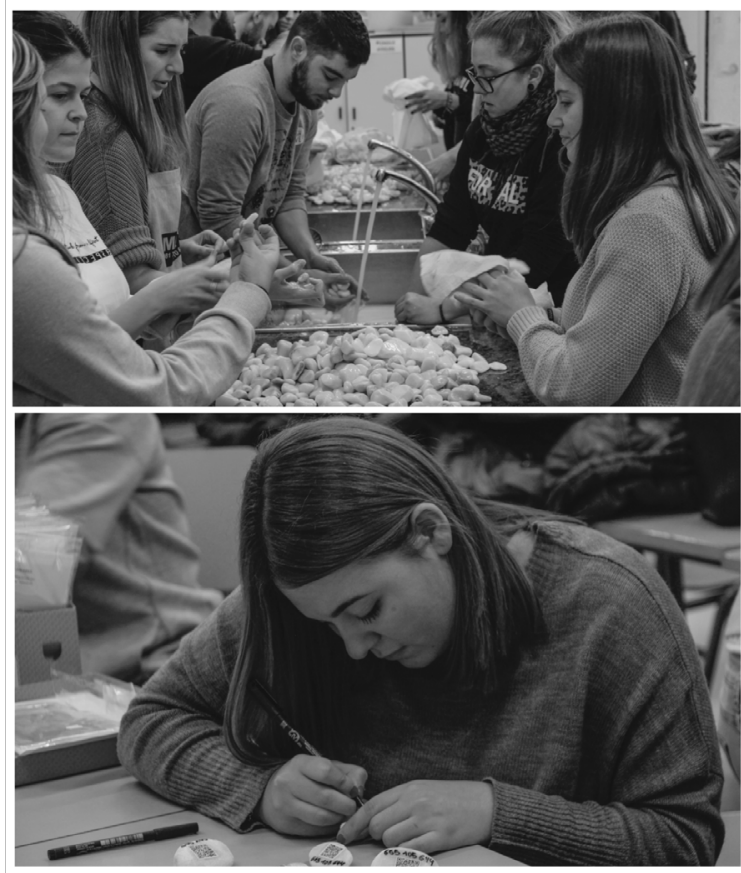

FIGURA I | Elección y preparación de la piedra como objeto simbólico FUENTE: ELABORACIÓN PROPIA 
En segundo lugar, se seleccionaron aquellos lugares que pudieran tener un discurso propio y diferente; es decir, aquellos creados con el fin de atender una necesidad humana y social, en resonancia con la premisa que da origen al proyecto (Ruiz, 2012). Estos son: museos; estaciones de autobús, de tren y aeropuerto; facultades, bibliotecas, hospitales; zonas de parque y jardín: Paseo Marítimo; y las cuatro avenidas principales que cruzan la ciudad: Oza, sita en una zona obrera; la Marina, ubicada en el centro de la ciudad; Finisterre, calle gentrificada por el crecimiento de la ciudad; y la Ronda de Outeiro, conectora de los extremos de la península que dibuja A Coruña.

Posteriormente, la creación de un cuestionario en que se solicitaba un pensamiento, una emoción o un sentimiento ligado al lugar donde se encontró la piedra, encriptado en un código QR adherido a la misma, posibilitó una conversación abierta, donde la escucha de las emociones que habitan los lugares, la necesidad de expresar y la búsqueda del otro, se configuran como motores del diálogo.

A continuación, entre los meses de enero y abril de 2017, el alumnado realizó un mapeo sistemático de los lugares seleccionados en la ciudad de A Coruña (figuras 2 y 3). Para ello utilizaron media tonelada de piedras de mediano tamańo, que contenían, en el anverso, un mensaje personal meditado y escrito por los estudiantes; y en el reverso, un código QR, que -tal y como se explicó- redirigía a las personas al cuestionario en el que podían depositar de forma anónima su mensaje de situación emocional. En este contexto, los espacios urbanos comenzaron a hablar, recibiéndose un total de 244 mensajes de respuesta.
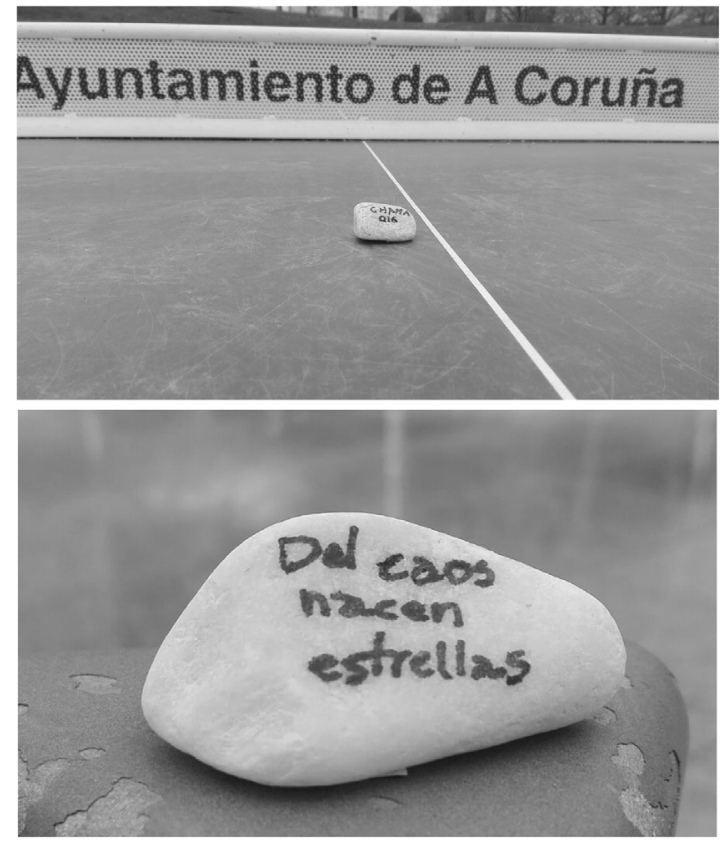

FIGURA 2 | Cartografía de la ciudad

FUENTE: ELABORACIÓN PROPIA 

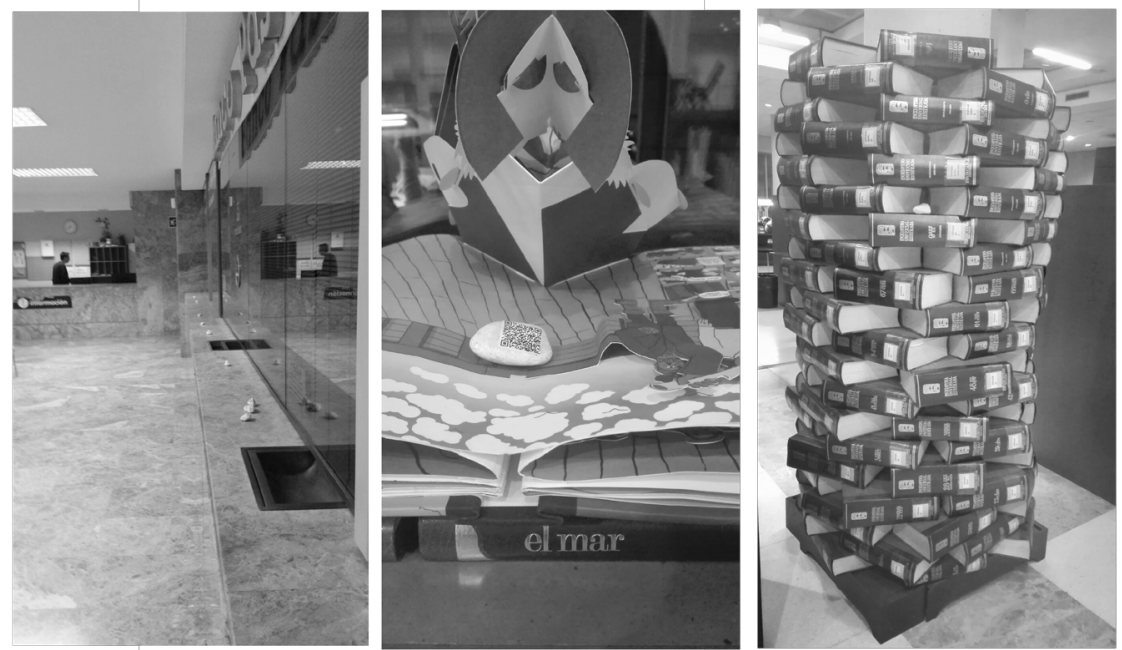

FIGURA 3 | Piedras a la deriva

FUENTE: ELABORACIÓN PROPIA

La incerteza de obtener o no contestación, y la exigencia de sostener una conversación con un interlocutor indefinido, generaron inquietud inicial entre los participantes; no obstante, las respuestas casi inmediatas de las personas y la presencia continuada del proyecto en las redes sociales (Twitter, Instagram y WhatsApp), a través de imágenes y comentarios, favorecieron la continuidad de la acción, en la celebración diaria del acto comunicativo. La curiosidad de los comunicantes actuó como motor poderoso de deseo y permanencia ante la frustración.

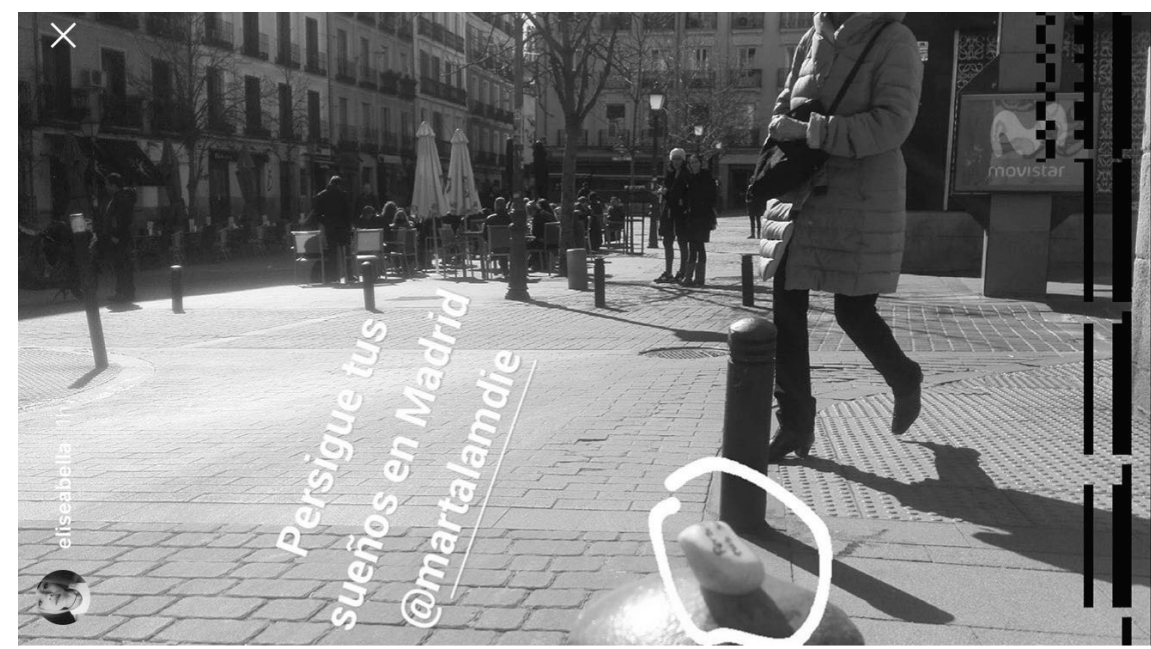

FIGURA 4 | La voz del lugar, el eco

FUENTE: ELABORACIÓN PROPIA 
Una deriva inesperada del proyecto fue la movilidad de las piedras, las cuales viajaron a diferentes ciudades de Europa (figura 4). Las redes sociales permitieron realizar un seguimiento a través de las imágenes que compartían las personas que las encontraron en sus ciudades o las transportaron.

Asimismo, en las facultades de Derecho y de Educación de A Coruña diferentes personas han depositado, a modo de respuesta, nuevas piedras sin código QR, con el fin de continuar la iniciativa.

\section{Participantes}

En el proyecto artístico "El lugar de la voz, la voz del lugar", participaron, como emisores, 51 estudiantes de servicios a la comunidad (6 hombres y 45 mujeres), quienes actuaron como comunicadores de sus pensamientos y sentimientos. Al otro lado de la conversación, se situaron los habitantes de los lugares seleccionados por los estudiantes (Ruiz, 2012), quienes participaron relatando sus vivencias de modo anónimo.

Una profesora del área de artes y humanidades participó coordinando el desarrollo del proyecto en el propio escenario, organizando a los grupos, canalizando las respuestas, orientando la intervención en todo momento y redactando el informe de resultado.

\section{Análisis cartográfico de las voces dialogadas}

Con el propósito de analizar el discurso ciudadano, se empleó una variante de la metodología de estudios de panel (Sun Woong, 2008), denominada "de cohorte" (De Keulenaer, 2008). Dicha elección se basa en la búsqueda del equilibrio entre los denominados estudios longitudinales y las dificultades para lograr una implicación y participación prolongadas (Lavrakas, 2008) entre quienes han experimentado un determinado evento (Martínez-Vérez, Abad, \& Hernández, 2017). En esta ocasión, a los participantes en la cartografía ciudadana descrita se les solicitó que compartieran de modo anónimo un sentimiento, un pensamiento o una emoción ligados al lugar donde hallaron el objeto simbólico, con el fin de "desenmarañar los hilos de la experiencia pasada y presente” (De Miguel, 2012, p. 39). Una vez obtenidas las respuestas, se las clasificó por lugares y los investigadores analizaron los mensajes compartidos de acuerdo con la propuesta fenomenológica de Vidal (2006a, 2006b). Esta promueve la utilización de formas no convencionales de conocer, como la subjetividad y la intuición, procesos necesarios, según Goodman (1990), para generar resultados adecuados a los patrones artísticos. De este modo permiten determinar si el discurso de las personas es diferente según el lugar que habitan diariamente o si, por el contrario, habitantes y voces se confunden, con independencia del espacio social en el que surge la palabra.

\section{Análisis y resultados: cartografías ciudadanas, voces de alteridad tejidas al lugar} Si los lugares hablaran, ¿qué relatos contarían? La necesidad social que atiende el espacio, ¿afecta la voz de las personas que lo habitan? ¿O simplemente sucede que los humanos contamos lo mismo aquí y allá? 
Estas preguntas, formuladas alguna vez por todos nosotros en la intimidad del pensamiento, son respondidas por las voces de los habitantes anónimos, en una suerte de cartografía ciudadana del pensamiento simbólico y la emoción humana que hace estallar el discurso, generando una obra plena (Guillaumin, 1981). Así, poco a poco, en este apartado, los autores van desgranando las voces de la ciudadanía.

Atendiendo a los lugares escuchados, se destacan las emociones y sentimientos que a continuación se detallan.

En los museos existe una diferencia entre los discursos de las personas que participan habitualmente en los talleres propuestos, quienes destacan la experiencia compartida a lo largo de un tiempo - "Tarde soleada y de charla", "Es importante comunicarse y sentir con otros", o "Gracias por compartir la experiencia vital"- y los mensajes de los visitantes ocasionales, los cuales reflexionan individualmente acerca del poso emocional de las obras contempladas: "Hay lugares donde Tú eres infinito", "Aquí puedes descubrir, sentir, agradecer", o "Perderte y encontrarte a ti mismo". También es frecuente encontrar proclamas que llaman a la acción, como "Luchar por la identidad, más arte para la educación"; "Abrir mentes, atreverse, compartir"; o "Hay que formar la autocrítica y la convicción, son esenciales para la vida".

En las bibliotecas, sin embargo, la calma abre paso a los sentidos, la memoria sensorial cobra protagonismo en el silencio de la escena, se habla de lo que se ve: "La luz que entra a toneladas, junto a un interesante skyline de A Coruña"; de lo que se oye: "Ese silencio interrumpido por las pisadas de los otros"; de la sensación táctil que despiertan los objetos: "Las hojas de los libros son ásperas"; y de los aromas: "Olor peculiar a libros almacenados". Otros aspectos narrados en los mensajes escritos en las bibliotecas remiten a la expectativa de la lectura elegida: "Cada libro es una promesa de felicidad", "Qué contarán estas páginas..."; y a la transgresión que se saborea al alterar el uso del espacio: "Adoro comer a escondidas, mientras leo".

Por último, respecto al proyecto, se destaca la voz sorpresiva y alegre de una bibliotecaria, quien, al encontrar las piedras, relata: "Me emociona la vida que tiene este centro: existen personas desconocidas con todo tipo de inquietudes".

Mientras las bibliotecas relatan los aromas de las horas delgadas del estudio y la lectura, los hospitales, en función de la situación del paciente, manejan diversas emociones. Tras asumir la incerteza del resultado de una cirugía, las personas se preguntan por la posibilidad de perder a un ser querido, anticipando la tristeza de la pérdida: "Hoy le operan y si muere...". Se alegran del diagnóstico favorable: "Pendientes de resultados en urgencias, al final, todo bien, ánimo". Y se indignan ante el infortunio: "Operación familiar y búsqueda de respuestas. Otra piedra más en mi camino".

Los sentimientos derivados de la aceptación de la enfermedad son suaves en la elección de las palabras y recogen aspectos sensoriales de meditación profunda. Así, una mujer enferma de cáncer se desea a sí misma la tranquilidad futura: "He disfrutado de una tarde feliz en compañía de mi hijo y mi nuera, después de pasar varios días ingresada a causa de un tratamiento de radioterapia; horas de paz y sosiego, como desearía para mí el resto de mis días". También se observa cómo la calma 
del paisaje (el hospital está situado frente al océano) favorece el manejo suave de la tensión - "El mar me inspira calma, a pesar de su bravura"-, ya que "Saborear estos pequeños detalles de la vida es lo más importante del mundo".

En las facultades de Educación, los estudiantes gritan proclamas de rebeldía, nos llaman a "ser libres", a "decir lo que se piensa sin miedo"; "a luchar fuerte por nuestros derechos y libertades". Piden la no rendición: "Sigue adelante, ya que si la raíz es fuerte, la planta no muere"; y reflexionan sobre la educación como "la mejor herramienta para alcanzar la justicia y el cambio". También aparecen mensajes de queja como mecanismo de defensa del yo: "Me siento frustrado por la mala organización [del] máster". Y otros que reflejan un mal manejo de la tensión derivada de la fase de evaluación: "Estrés, solo estrés, nervios y exámenes". Algunos revelan un contraste negativo de expectativa: "Llegas con esperanza y ganas, te percatas de la monotonía y piensas en superarte, terminar y salir lo antes posible de este lugar". Y se escucha también la voz de la pertenencia propia del alumnado que está terminando su formación: "La ciudad y la facultad siguen sin gustarme, pero les tengo cierto cariño porque forman parte de lo soy y seré"; o: "Quizás las vivencias del camino sean lo más valioso del proceso de aprendizaje; por ello, siempre habrá una parte de este lugar en mi vida”.

Los profesores tienden a reflexionar en voz alta sobre el proyecto. Dicen: "Estas piedras son especiales, hablan, tienen historias dentro de ellas". O: "Hoy vi a una mujer dibujar con piedras en el pasillo. Nunca antes lo había visto. Me hizo pensar en las posibilidades". Y también hablan acerca del simbolismo de la piedra como un objeto oceánico, "capaz de transformar el paisaje". O aparecen pensamientos que invitan a la calma en contra de la implosión continua propia de la posmodernidad, y guardan relación con los mensajes escritos a mano en el envés de las piedras. Dicen, por ejemplo: "Al encontrar y leer la frase 'detén el tiempo', pensé que quisiera parar el reloj para disfrutar de las situaciones o para poder reflexionar sobre ellas". O se refieren a la alteridad: "La piedra decía 'fragilidad' y pensé que al revelarnos como frágiles ante otras personas les otorgamos el mayor voto de confianza, pueden dañarnos o curarnos".

Por último, se observan también pensamientos relacionados con la carrera docente y el orgullo de la pertenencia a una institución y a una profesión: "Esta piedra me invita a pensar y yo me hallo en un centro del pensamiento; aquí pensamos la educación, enseńamos a generaciones venideras lo que sabemos, les ayudamos a trazar su camino. Somos profesores".

En los transportes públicos, trenes, autobuses y aviones, las voces de los pasajeros se centran en las distintas posibilidades que ofrece realizar un trayecto. Así, por ejemplo, hablan acerca del paisaje que se observa, se encuentran mensajes placenteros: "Regresar a casa, viendo el atardecer, es maravilloso"; "Coruña es fusión de mar y ciudad"; y "Volver del trabajo, mirando el mar, es un privilegio". Otros destacan el anonimato: "La gente que me rodea es desconocida y los destinos son múltiples; se divisan miradas perdidas sin ganas de encontrarse y alguna que otra buscando su lugar". También las personas relatan lo que piensan mientras observan el interior del transporte: "Voy y vengo cada día a trabajar en tren, me gusta estar 
aquí, observar a las personas en su día a día. Si tuviese que elegir un lugar para repensar mi vida, sería este".

La experiencia laboral forma parte de muchos pensamientos, en ocasiones centrados en la rutina: "A trabajar, como cada día... no apetece...". Otras, en la percepción de aquello que se anhela: "Cada domingo yendo a trabajar y sońando con un trabajo estable". Y en la oportunidad de comenzar de nuevo con ánimo renovado: "Nueva experiencia laboral, afrontar los cambios sin miedo, prohibido rendirse".

Las cuatro grandes avenidas que cruzan A Coruña y la definen en flujos de comunicación, tanto de tráfico rodado como peatonal, cruzan los relatos de los ciudadanos en torno a varios sentimientos, como la pertenencia propia de la ciudadanía: "Aquí, junto al mar, nacieron y crecieron mis hijos"; o "Esta esquina [calle Riazor] guarda la memoria de los años más importantes de mi vida. No me ha pedido permiso para hacerlo. Tampoco tenía por qué". La ausencia y el recuerdo de los seres queridos: "Miro el horizonte y recuerdo a la que fue y es la mujer de mi vida. Cierro los ojos y estás aquí, todavía formas parte de mí, irremediablemente. Hace tiempo que no estás conmigo, y aun así, te sigo amando". Y hablan de la presencia de quienes sí están ahora: "Siempre es un placer contemplar las olas, aunque lo mejor últimamente no es el paisaje, sino la persona que me acompaña”.

En concreto, el Paseo Marítimo, que rodea el contorno de la ciudad, es un espacio que invita a contemplar y a contemplarse, "a nacer y despertar, a dejar ir, fluir, apartar a un lado, reencontrarme y reconocerme".

Atendiendo a la poética urbana, se destaca un mensaje entre todos los recibidos, tanto por el tiempo dedicado a la escritura como por la historia y la calidad de las palabras elegidas para narrarla:

El semáforo da verde, cruzo la cebra; ella, desconocida, viene en dirección contraria y entierra la llama onírica de sus ojos verdes, mira hasta el final, me roza suave el brazo con su hombro, no gira la cabeza, pero modifica el tiempo, lo suaviza, lo ralentiza. Yo miro al frente, piedra en mano, repito el texto, lo único que quiero es un beso tuyo. Sonrío, vuelvo a casa, y sé que desde hoy los días serán mejores. Todo está en movimiento.

Los parques y las zonas de recreo hablan a través de las voces de las madres que relatan el juego de sus hijos: “- ¡Mamá, mira, un dragón! ¡Quiero subir y que salga volando! ¿Me ayudas? -Y él (en su estatua), impertérrito, deja que se le suban al lomo, e incluso parece que disfruta”.

Describen el sentimiento de recibir el regalo de una piedra con mensaje: "Me la regaló mi hija Elena por el día de la madre; la piedra pone 'sé feliz' y eso haré, gracias".

Aparecen también mensajes de parejas adolescentes que, recién descubierto el amor, comparten la fábrica de los primeros recuerdos: "En este banco nos dimos el primer beso"; "Aquí te conocí", "Te amo".

Entre los mensajes alegres recogidos en las zonas de recreo, destaca uno de crueldad inédita, en cuanto a que la persona que escribe no parece ser consciente del daño provocado, y solo pone el acento en la diversión vivida: "Recuerdo ser 
pequeño cuando ocurrió. Había un chaval, Catoira, le hacíamos bullying fuerte. Demasiado. Éramos unos verdaderos cabrones, pero nos lo pasábamos muy bien”.

\section{Discusión, conclusiones y proyecciones}

\section{Discusión}

La comunicación, inevitable e interpersonal, se caracteriza por ser significativa, en la necesidad que tiene de ser comprendida (Segura \& Simó, 2017); simbólica, en cuanto es hija de un flujo interpretativo (López Fernández-Cao \& Gauli, 2000); y emocional, por cuanto conmueve a quienes la atienden (Beavin, Jackson, \& Watlawich, 2002).

En este apartado, cercano a la discusión científica, se realiza una triangulación entre el discurso ciudadano, la interpretación de los autores y el marco teórico, con el fin de engarzar los procesos comunicativos en la geografía emocional, a través de un recorrido por la función social de la arquitectura urbana.

Escuchar la voz de las personas que habitan los espacios urbanos permite establecer un vínculo entre la función social del lugar, el imaginario del arquitecto o arquitecta y las palabras de la ciudadanía, que es quien, en definitiva, a través de su pensamiento, emoción y acción, da forma a los espacios, transformándolos en lugares, en una suerte de creación relacional del nosotros colectivo (Gersen \& Gersen, 2004). Y es que existe una diferencia entre ocupar un espacio y tener un lugar. Así, mientras los espacios se trazan en coordenadas físico-temporales, los lugares se habitan en coordenadas socioafectivas. Un espacio solo es lugar cuando genera vínculo. En este sentido, se podría afirmar que cualquier persona puede llegar a conocer la geografía de un territorio, pero únicamente los ciudadanos pueden amarlo.

Atendiendo al tipo de lugar, se observa que la función social, el uso para el cual fue concebido, conduce el pensamiento de los habitantes hacia diferentes emociones, ya que, tal y como señala Madrid (2013), en lo simbólico del pensamiento las partes han de tener sentido. Así, se puede decir que existe un equilibrio, una dulzura sensata entre los relatos de los actores y la arquitectura que sostiene el lugar en su función y estructura, como si se tratara de una viga maestra, una clave de bóveda, oculta en la caja de resonancia del espacio (Gueyrand, 2015). De este modo, no solo las palabras sueñan que se las nombra (Bachelard,1982), también los lugares son reclamo de ensońación y discurso socioafectivo (Berger \& Luckman, 1972).

Así, por ejemplo, los hospitales enfrentan la enfermedad desde las diferentes fases en las que ella transcurre, apareciendo la incertidumbre ante el diagnóstico y la cirugía, la negación ante la certeza del afrontamiento, y la serenidad en la aceptación (Durán, 1999).

Por su parte, tanto las facultades de Educación como los museos promueven la acción educativa a través de la proclama, aspecto ético vinculado con el pensamiento propio de las personas que trabajan, visitan o se educan en dichos lugares. Aparece también la reflexión individual en torno a la percepción, tanto acerca del proyecto como del día a día. 
En los medios de transporte y las avenidas que cruzan la ciudad, los pensamientos se conducen en variables de pertenencia (habitante), introspección (vivencia), memoria (ausencia y presencia del Otro) y sensorialidad (disfrute de aquello que se percibe en abundancia).

Las bibliotecas, centradas en el estudio y la lectura, permiten el silencio interior y nos remiten a la sensorialidad, a la percepción sensorial y a la expectativa respecto de las páginas que todavía esperan ser leídas.

En todos los lugares aparecen pensamientos que demandan tiempo, calma y tranquilidad para saborear, reflexionar y vivenciar los acontecimientos. Estos, en el marco de la sociedad posmoderna, desbordan el tiempo y espacio que el ser humano puede gestionar (Cyrulnik, 2002), ya que, en la contemporaneidad, la identidad se teje en un proceso continuo de construcción del vínculo social.

Hay también cavilaciones que incluyen la alteridad (Ortega, 2016), el Otro como instancia o lugar del Yo. Aparecen especialmente en los lugares abiertos, que permiten que el paisaje se asome al interior de las personas, favoreciendo la exteriorización de los sentimientos relacionados con la experiencia corporal del yo en el otro (Kapuscinski, 2012), concretada en la certeza del encuentro (Greimas \& Fontanille, 1994). En este sentido, las personas manifiestan su preferencia por estos espacios para declarar el amor, llorar el desamor, justificar la propia crueldad, anhelar ausencias y colmarse en las presencias de los otros que nos acompañan, ya que el arte posee un orden oculto, un sustrato polifónico, no una línea unívoca de pensamiento (Ehrenzweig, 1973).

Por último, la permanencia, continua o discontinua, del espacio y su uso, traza diferencias en el discurso de las personas. Así, se observa que la voz de los habitantes que trabajan para ejecutar la función social del lugar -mujeres y hombres que ejercen de bibliotecarios, médicos, enfermeros y profesores- es distinta a la de quienes, simplemente, se agrupan para hacerla realidad en sí mismos: estudiantes, pacientes y alumnos. Mientras que los primeros centran su voz en el día a día, explicando su trabajo desde su perspectiva de vida y su contexto emocional (McEwan \& Egan, 1998), los segundos reflexionan acerca del poso que el lugar y el tiempo dejan en su memoria afectiva, en su proyecto de vida y en su propia construcción social y humana, ya que de cada hábitat emana una madeja de relaciones en torno a la necesidad de habitar un mundo común, concretado en las arquitecturas que creamos para ello (Bourriaud, 2006).

\section{Conclusiones}

La cartografía de las ciudades, su urbanismo, la arquitectura de los espacios, son el mapa de sus habitantes. Existe una interacción entre las voces de las personas y los lugares.

Los lugares hablan. Con voz propia. Tienen un discurso social que los distingue. Son memoria viva, de incertezas, dudas, emociones, denuncias, proclamas, e incluso expectativas. Son historias de materia y átomos de palabra. Fusión de cemento y personalidad.

En ese discurso, algunos espacios tienen una función tan clara y definida, que sus habitantes solo pueden serlo en la medida en que contribuyen a que ella se realice. 
En los espacios creados para curar, para educar, para reflexionar, los pensamientos de las personas que permanecen, organizando la función del lugar, se diferencian de los relatos de aquellas que los utilizan para hacerla efectiva en sí mismos. Así, mientras los primeros hablan de su trabajo, del día a día, de la disrupción de la rutina; los segundos comparten emociones derivadas de su propia expectativa como usuarios temporales de los mismos.

Los espacios urbanos recogen voces de pertenencia al lugar, a la ciudad, a la intrahistoria que tejemos en torno a los callejeros. Son otro tipo de arquitectura, viva y habitada, sin la cual la ciudad no existiría.

\section{Futuras líneas de investigación}

El resultado más interesante de este estudio es la certeza de la voz del lugar, del cual se derivan otras posibilidades que, como coordenadas témporo-espaciales, podrían ser objeto de nuevas investigaciones.

En este sentido, la voz de los templos, especialmente de aquellos en los que el culto está vivo en forma de devoción, peregrinación o discurso museístico, todavía está en silencio. ¿Será de hombre o de mujer? ¿Qué fórmula adoptarán las oraciones? ¿A quién se dirigirán?

Y dentro de un lugar, por ejemplo, un hospital, ¿existirán diferencias palpables en las voces de los distintos espacios?

Otra cuestión interesante es la longitudinalidad del objeto de estudio: el tiempo, el transcurrir de los ańos y las generaciones, ¿generará nuevos usos sociales que alterarán el pensamiento vivo del lugar?

Asimismo, imaginar el uso anterior del lugar y el por-venir del mismo, abriría espacio para un debate rico en opciones y posibilidades.

En resumen, este trabajo indagativo y curioso constituye un principio narrativo, a partir del cual la escucha activa dará lugar a nuevas investigaciones.

\section{Referencias bibliográficas}

Bachelard, G. (1982). La poética de la ensoñación. Madrid: Fondo de Cultura Económica de España.

Bartolomé, M. (2017). Diversidad educativa ¿Un potencial desconocido? Revista de Investigación Educativa, 35(1), 15-33. http://dx.doi.org/10.6018/rie.35.1.275031

Beavin, J., Jackson, D., \& Watzlawich, P. (2002). Teoría de la Comunicación Humana. Barcelona: Herder.

Berger, P. \& Luckman, T. (1972). La construcción social de la realidad. Buenos Aires: Amorrurtu. Bergson, H. (1985). La evolución creadora. Madrid: Espasa-Calpe.

Bourriaud, N. (2006). Estética relacional. Buenos Aires: Adriana Hidalgo editores.

Cyrulnik, B. (2002). El encantamiento del mundo. Barcelona: Gedisa.

De Bustos, E. (2000). La metáfora. Ensayos interdisciplinares. Madrid: Fondo de Cultura Económica de España / Universidad Nacional de Educación a Distancia. 
De Keulenaer, F. (2008). Panel Survey. En P. J. Lavrakas (ed.), Enciclopedy of Survey Research Methods (pp. 570-573). Thounsand Oaks, ca: Sage.

De Miguel, L. (2012). Investigación/Arte/Vida: entre intersticios, procesiones y progresiones. Arterapia: Papeles de arterapia y educación artística para la inclusión social, 7, 27-40. http://dx.doi.org/10.5209/rev_ARTE.2012.v7.40759

Durán, M. Á. (1999). Los costes invisibles de la enfermedad. Madrid: Fundación BBVA (2a ed.) 2002. https://bit.ly/2YyzUqR

Ehrenzweig, A. (1973). El orden oculto del arte. Barcelona: Labor.

Garro-Larrañaga, O. (2014). El arte y la construcción social del sujeto: una reflexión con Nan Goldin acerca de las narrativas familiares. Arte, Individuo y Sociedad, 26(2), 255-269. http://dx.doi.org/10.5209/rev_ARIS.2014.v26.n2.41457

Gergen, K. J. \& Gergen, M. (2004). Reflexiones sobre la construcción social. Barcelona: Paidós Ibérica.

Giráldez, A. \& Prince, S. (2017). Habilidades para la vida: aprender a ser y aprender a convivir en la escuela. Madrid: SM.

Goodman, N. (1990). Maneras de hacer mundos. Madrid: Visor.

Greimas, A. J. \& Fontanille, J. (1994). Semiótica de las pasiones. México, DF: Siglo XxI.

Gueyrand, B. (2015). La palabra en el camino. Arteterapia: Papeles de arteterapia y educación artística para la inclusión social, 10, 87-104. http://dx.doi.org/10.5209/rev_ ARTE.2015.v10.51685

Guillaumin, J. (1981). Los sueños y el yo. Barcelona: Paidós.

Kapuscinski, R. (2012). Encuentro con el otro. Barcelona: Anagrama.

Kara, H. (2015). Creative research methods in social sciences. Bristol, UK: University of Bristol Policy Press.

Kramp, M. (2004). Exploring life and experience through narrative inquire. Mahwah, NJ: Eribaum.

Lavrakas, P. (2008). Panel Fatigue. En P. J. Lavrakas (ed.), Encyclopedia of Survey Research Methods (pp. 569-570). Thounsand Oaks, ca: Sage.

López-Cao, M. (2014). Memoria, ausencia e identidad. Madrid: Eneida.

López-Cao, M. \& Gauli, J.C. (2000). El cuerpo imaginado. Revista Complutense de Educación, 11(2), 43-57. https://revistas.ucm.es/index.php/RCED/article/view/ RCED0000220043A

Macaya, A. (2017). Trayectos en el mapa: artes visuales como representación del conocimiento. Arte, Individuo y Sociedad, 29(2), 387-404. http://dx.doi.org/10.5209/ARIS.55105

Madrid, M. (2013). Investigando con otros: la investigación en educación artística como praxis de la diferencia. Arte, Individuo y Sociedad, 25(2), 261-270. http://dx.doi.org/10.5209/ rev_ARIS.2013.v25.n2.39023

Martínez-Vérez, M. V., Abad, J., \& Hernández, D. (2017). El telar de la desmemoria y la metáfora del bordado. Arte relacional desde una perspectiva intergeneracional y de género. Arte, Individuo y Sociedad, 29(número especial), 223-238. http://dx.doi. org/10.5209/ARIS.53646

Mc Ewan, H. \& Egan, K. (1998). Compilación. La narrativa en la enseñanza, el aprendizaje y la investigación. Buenos Aires: Amorrortu.

Mora, F. (2013). Neuroeducación. Solo se puede aprender aquello que se ama. Madrid: Alianza. 
Moreno, A. (2015). Arte como herramienta social y educativa. Revista Complutense de Educación, 26(2), 315-329. http://dx.doi.org/10.5209/rev_RCED.2015.v26.n2.43060

Ortega, P. (2013). La pedagogía de la alteridad como paradigma de la educación intercultural. Revista Española de Pedagogía, 256, 401-422. https://bit.ly/2LCHCg1

Ortega, P. (2016). La ética de la compasión en la pedagogía de la alteridad. Revista Española de Pedagogía, 264, 433-264. https://bit.ly/2Yysmoc

Ruiz, J. L. (2012). Metodología de la investigación cualitativa. Bilbao: Universidad de Deusto.

Segura, J. \& Simó, T. (2017). Espacialidades desbordadas. Arte, Individuo y Sociedad, 29(2), 219-234. http://dx.doi.org/10.5209/ARIS.47854

Tejo, C. (2017). Proyectos de arte de acción: análisis de una experiencia pedagógica. Arte, Individuo y Sociedad, 29(2), 203-217. http://dx.doi.org/10.5209/ARIS.47320

Terrones, A. (2013). Usar en caso de performance. Estudio del proceso creativo en el arte de acción. Efimera, 4(5), 32-41. https://dialnet.unirioja.es/servlet/articulo?codigo=5032232

Sun Woong, K. (2008). Panel. En P. J. Lavrakas (ed.), Encyclopedia of Survey Research Methods (pp. 564-566). Thounsand Oaks: Sage.

Vidal, R. (2006a). Discursos feministas y condición postmoderna. Revista de Investigaciones Politicas y Sociológicas, 5(1), 25-38. https://dialnet.unirioja.es/servlet/ articulo? codigo $=2237688$

Vidal, R. (2006b). Discurso feminista y temporalidad. La descomposición postmoderna de las identidades de género. Revista de Ciencias Sociales, 194, 95-108. https://dialnet. unirioja.es/servlet/articulo? codigo $=273062$

Zaliasnik, Y. (2017). Villa o cómo practicar (y abrir o ampliar) un lugar y sus memorias a través de la teatralidad. Revista Alpha, (44), 221-222. http://dx.doi.org/10.4067/S071822012017000100221

Zaragoza, J., Luis-Pascual, J. C., \& Manrique, J. C. (2009). Experiencias de innovación en docencia universitaria: resultados de la aplicación de sistemas de evaluación formativa. Revista de Docencia Universitaria, 7(4), 1-33. https://doi.org/10.4995/redu.2009.6232 